\title{
Renal and Splenic Infarction: Unusual Manifestation of the Antiphospholipid Syndrome
}

\author{
ELIZABETH F DAHER ${ }^{1}$, RAFAEL S.A. LIMA ${ }^{2}$, ANA CRISTINA L. MELO ${ }^{3}$, GERALDO B SILVA JUNIOR ${ }^{4}$
}

\begin{abstract}
Antiphospholipid syndrome is a multisystem disorder characterized by recurrent thromboses in the arterial system, venous system, or both. A 42-year-old man sought treatment reporting two episodes of abdominal pain in the right flank radiating to his back associated with nausea and vomiting fifteen days prior to admission. Abdominal CT with contrast showed left renal atrophy, renal right and splenic infarction. Laboratory tests showed worsening of renal function after CT contrast: serum creatinine $0.6 \mathrm{mg} / \mathrm{dL}$ to $5.5 \mathrm{mg} / \mathrm{dL}$. The complementary investigation showed anti-cardiolipin antibodies (aCL) positive in high titers; antinuclear antibodies, myeloperoxidase-antineutrophil cytoplasmic antibody, anti-nuclear antibody, serology for hepatitis A, B and C, ELISA anti-HIV and VDRL were negative. A diagnosis of renal and splenic infarction due to antiphospholipid syndrome was made and the patient received treatment with subcutaneous heparin followed by warfarin.
\end{abstract}

Key-words: Antiphospholipid syndrome, renal infarction, splenic infarction

\section{Introduction:}

Antiphospholipid syndrome (APS) is an autoimmune disorder characterized by recurrent thromboses in the arterial system, venous system, or both and/or pregnancy losses, in the presence of persistently elevated levels of anticardiolipin antibodies (aCL) and/or evidence of circulating lupus anticoagulant (LA). ${ }^{1}$ The kidney is a major target organ in patients with the APS. The renal manifestations may result from thrombosis occurring at any location within the renal vasculature, including the renal artery trunk or branches, intraparenchymal arteries and arterioles, glomerular capillaries, and the renal veins. ${ }^{1} \mathrm{We}$ report the case of renal and splenic infarction due to antiphospholipid syndrome.

\section{Case report:}

A 42-year-old man sought treatment reporting two episodes of abdominal pain in the right flank radiating to his back associated with nausea and vomiting fifteen days prior to admission. Laboratory tests showed serum creatinine: $0.6 \mathrm{mg} /$ $\mathrm{dL}$ and urea: $30 \mathrm{mg} / \mathrm{dL}$. Chest and abdominal $\mathrm{CT}$ with contrast

1. Department of Internal Medicine, Federal University of Ceara. Fortaleza, Ceara, Brazil.

2. Department of Internal Medicine, School of Medicine of Ribeirão Preto, University of São Paulo. Ribeirão Preto, São Paulo, Brazil

3. Division of Nephrology, General Hospital of Fortaleza. Fortaleza, Ceará, Brazil

4. Department of Internal Medicine, School of Medicine, Federal University of Ceara, Ceará, Brazil.

Correspondence: Geraldo B Silva Junior, Department of Internal Medicine, School of Medicine, Federal University of Ceara, Ceará, Brazil.E-mail: geraldobezerrajr@yahoo.com.br showed left renal atrophy, renal right and splenic infarction. After CT contrast, new laboratory tests showed serum creatinine: $5.5 \mathrm{mg} / \mathrm{dL}$ and urea: $124 \mathrm{mg} / \mathrm{dL}$. Urinalysis revealed $1+$ protein, $2+$ white blood cells and $4+$ red blood cells. The complementary investigation showed anti-cardiolipin antibodies (aCL) positive in high titers; antinuclear antibodies (ANA), myeloperoxidase-antineutrophil cytoplasmic antibody (c-ANCA) and anti-nuclear antibody (ANA) were negative. The serology for hepatitis A, B and C negative; ELISA anti-HIV and VDRL were also negative. The urinary protein excretion was $1.44 \mathrm{~g} / 24 \mathrm{~h}$ and creatinine clearance was $39 \mathrm{~mL} / \mathrm{min} / 1,73 \mathrm{~m}^{2}$. A diagnosis of renal and splenic infarction due to antiphospholipid syndrome was made and the patient received treatment with subcutaneous heparin followed by warfarin.

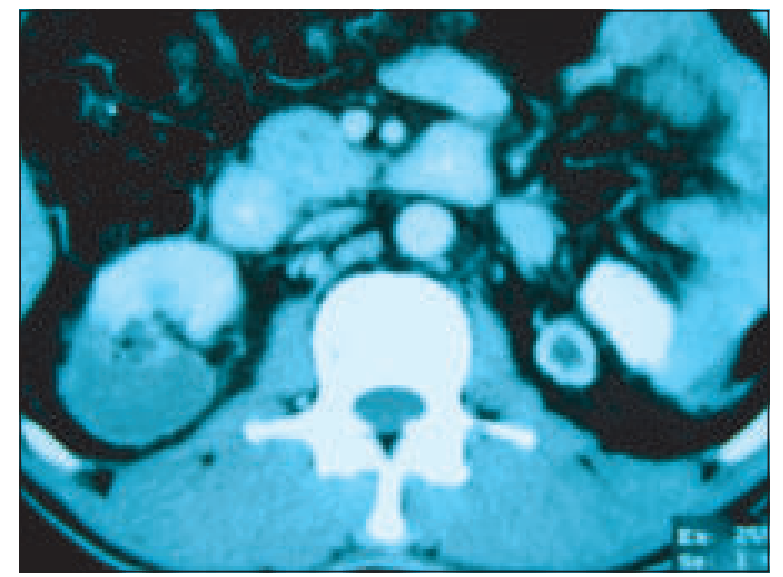

Fig.-1: Computer tomography showing renal infarction and atrophic kidney. 


\section{Discussion:}

The antiphospholipid syndrome (APS) was first described by Hughes in the 1980s as a disorder of hypercoagulability in association with antiphospholipid antibodies. ${ }^{1}$ APS may occur, though less frequently, in the absence of associated autoimmune disease, the so-called primary APS. The diagnosis of APS is made when the patient fulfils at least one clinical (vascular thrombosis or pregnancy morbidity) and one laboratory [LA, aCL and/or anti- $\beta 2$-gylycoprotein1 (anti-â2GP1) antibodies] criterion. ${ }^{2}$

Arterial thromboses are less common than venous thromboses and occur in a variety of settings in patients with primary APS. Patients with arterial thrombosis most commonly present with transient ischemic attack or stroke $(50 \%)$ or myocardial infarction $(23 \%))^{3}$ The renal manifestations of APS thus may include renal artery stenosis (RAS) and/or renovascular hypertension, renal infarction, APS nephropathy (APSN), renal vein thrombosis, and increased allograft vascular thrombosis. ${ }^{4}$ All vascular structures of the kidney may be affected, leading to diverse clinical consequences including severe hypertension, proteinuria, hematuria, nephrotic syndrome, and renal failure. In some instances end stage renal disease (ESRD) may occur. ${ }^{5}$

\section{Conflict of Interest: None.}

\section{References:}

1. Hughes GR. Thrombosis, abortion, cerebral disease, and the lupus anticoagulant. Br Med J 1983; 287: 1088-1089.

2. Miyakis $\mathrm{S}$, Lockshin MD, Atsumi $\mathrm{T}$ et al. International consensus statement on an update of the classification criteria for definite antiphospholipid syndrome (APS). J Thromb Haemost 2006; 4: 295-306.

3. Cervera R, Piette JC, Font J, et al. Antiphospholipid syndrome: clinical and immunologic manifestations and patterns of disease expression in a cohort of 1,000 patients. Arthritis Rheum 2002; 46: 1019-1027.

4. Gigante A, Gasperini ML, Cianci R et al. Antiphospholipid antibodies and renal involvement. Am J Nephrol 2009; 30: 405-412.

5. Amigo MC. Kidney disease in antiphospholipid syndrome. Rheum Dis Clin North Am 2006; 32: 509-522. 